\title{
A design look at heritage silverware. Case study.
}

\author{
Keywords \\ Neogranadian silverware, silverware techniques, colonial history, History of material culture, Research-creation.
}

This participation presents the study of a pair of silverware lecterns from Nueva Granada, whose elaboration dates from the second half of the seventeenth century. Throughout the investigation, we made reflections about how the analysis of these artifacts, from the point of view of industrial design, allows us to see aspects that other disciplines study superficially, such as the close relationship between form, function and the production of an object. The objective of the research has been to understand the historical context of a society through the use of its objects, its symbolism and the dynamics of its manufacture. This research was developed in alliance with the Museo Colonial of Bogotá, which allowed direct access to the lecterns, a moment that constitutes a point of exploration; Unlike what can be the investigation of material culture from history or the history of art in its most traditional practices, the starting point is the artifact itself, which provides first-hand information both for its iconography and for its technical traces. Thanks to the iconographic analysis, it is possible to establish the "stories" contained in the pieces, and even their owners and context of use, despite the lack of regulatory colonial markings; Thanks to the observation of technical traces, it is possible to establish its production process and contrast it with current goldsmithing techniques. This contrast was made by the hand of an expert silversmith, which opened another look at the intangible heritage of the current trade of silversmithing in Colombia. Thanks to this study, it was possible to conclude that the role of silversmiths in New Granada was of vital importance for the purposes of the Spanish Crown to expand the Catholic religion throughout the Empire, thanks to its power in representation and capacity to capture the attention of the parishioners, due to the high level of decorative detail influenced by the Baroque movement. One of the most important aspects of the research was the development of different products that allowed the communication of the findings to different types of public: thus, the project had articles and participation in academic events, but also with the production of informative texts, museum material and a digital course in MOOC format, with audiovisual content. Therefore, this research is not only about the case study, but about how design can contribute from its own languages and resources to the recognition of the tangible and intangible heritage of a country. 